\title{
RNA sequencing reveals induction of specific renal inflammatory pathways in a rat model of malignant hypertension
}

\author{
Carlos Menendez-Castro ${ }^{1}$ - Nada Cordasic ${ }^{2} \cdot$ Fabian B. Fahlbusch $^{1} \cdot$ Arif B. Ekici $^{3}$ - Philipp Kirchner ${ }^{3}$. \\ Christoph Daniel $^{4} \cdot$ Kerstin Amann $^{4} \cdot$ Roland Velkeen $^{2} \cdot$ Joachim Wölfle $^{1} \cdot$ Mario Schiffer $^{2} \cdot$ Andrea Hartner $^{1} \mathbb{C}^{\circ}$ \\ Karl F. Hilgers ${ }^{2}$
}

Received: 25 March 2021 / Revised: 9 August 2021 / Accepted: 23 August 2021 / Published online: 15 September 2021

(c) The Author(s) 2021

\begin{abstract}
In malignant hypertension, far more severe kidney injury occurs than in the "benign" form of the disease. The role of high blood pressure and the renin-angiotensin-aldosterone system is well recognized, but the pathogenesis of the renal injury of malignant hypertension $(\mathrm{MH})$ remains incompletely understood. Using the rat model of two-kidney, one-clip renovascular hypertension in which some but not all animals develop $\mathrm{MH}$, we performed a transcriptomic analysis of gene expression by RNA sequencing to identify transcriptional changes in the kidney cortex specific for MH. Differential gene expression was assessed in three groups: $\mathrm{MH}$, non-malignant hypertension (NMH), and normotensive, sham-operated controls. To distinguish $\mathrm{MH}$ from NMH, we considered two factors: weight loss and typical renovascular lesions. Mean blood pressure measured intraarterially was elevated in $\mathrm{MH}(220 \pm 6.5 \mathrm{mmHg})$ as well as in $\mathrm{NMH}(192 \pm 6.4 \mathrm{mmHg})$, compared to controls $(119 \pm 1.7 \mathrm{mmHg}, p<0.05)$. Eight hundred eighty-six genes were exclusively regulated in $\mathrm{MH}$ only. Principal component analysis revealed a separated clustering of the three groups. The data pointed to an upregulation of many inflammatory mechanisms in MH including pathways which previously attracted relatively little attention in the setting of hypertensive kidney injury: Transcripts from all three complement activation pathways were upregulated in MH compared to NMH but not in NMH compared with controls; immunohistochemistry confirmed complement deposition in MH exclusively. The expression of chemokines attracting neutrophil granulocytes (CXCL6) and infiltration of myeloperoxidase-positive cells were increased only in MH rats. The data suggest that these pathways, especially complement deposition, may contribute to kidney injury under MH.
\end{abstract}

\section{Key messages}

- The most severe hypertension-induced kidney injury occurs in malignant hypertension.

- In a rat model of malignant hypertension, we assessed transcriptional responses in the kidney exposed to high blood pressure. A broad stimulation of inflammatory mechanisms was observed, but a few specific pathways were activated only in the malignant form of the disease, notably activation of the complement cascades.

- Complement inhibitors may alleviate the thrombotic microangiopathy of malignant hypertension even in the absence of primary complement abnormalities.

Keywords Malignant hypertension · Two-kidney one-clip renovascular hypertension (2K1C) · Kidney injury ·

Inflammation $\cdot$ Complement activation $\cdot$ RNA-Seq

\section{Introduction}

Arterial hypertension is one of the major risk factors for the development of cardiovascular disease [1]. Additionally, chronic elevation of blood pressure can induce chronic

Karl F. Hilgers

karl.hilgers@uk-erlangen.de

Extended author information available on the last page of the article kidney disease (CKD) [2]. Vice versa, renal disease causes arterial hypertension [3]. Malignant hypertension is characterized by a marked elevation of blood pressure and the occurrence of progressive end-organ damage (e.g., renal, cerebral, vascular, or ocular injury) $[4,5]$. In the kidney, malignant hypertension leads to a form of thrombotic microangiopathy, exhibiting fibrinoid necrosis and proliferative lesions of the small arteries [6] accompanied by kidney fibrosis and loss of renal function [7]. 
The pathomechanistic factors for the development of malignant hypertension in contrast to the development of non-malignant arterial hypertension are only incompletely understood. In animal models, a marked and rapid rise of blood pressure appears to be a necessary condition [8]. On the other hand, blood pressure differences between malignant hypertensive animals and appropriate non-malignant hypertensive controls can be quite small $[9,10]$. Griffin et al. reported that even a small reduction of blood pressure alleviated renal injury in a rat model of malignant hypertension, leading to the concept of a critical pressure threshold for malignant hypertension [5]. Several studies indicated that the activation of the renin-angiotensin-aldosterone system (RAAS) might play an important role [9, 11, 12]. A chronic activation of RAAS was also associated with the induction of inflammatory pathways [9, 13]. Furthermore, in a rat model of renovascular hypertension, malignant hypertension was accompanied by an impaired neovascularization and reduced capillary supply in heart and kidney tissue [14]. This might contribute to the specific vascular lesions and progressive organ failure seen in the kidney under malignant hypertension.

Here, we used a transcriptomic approach to elucidate specific alterations of gene expression of the kidney cortex in malignant versus non-malignant hypertension. We performed high-throughput RNA sequencing (RNA-seq) in a rat model of two-kidney, one-clip renovascular hypertension (2K1C) [15]. Thirty-five days after clipping, differential gene expression in renal cortex was assessed in three animal groups: rats with malignant hypertension $(\mathrm{MH})$, rats with non-malignant hypertension (NMH), and normotensive, sham-operated controls (sham). We focused on the nonclipped kidney exposed to hypertension, because it is the non-clipped kidney, which exhibits the characteristic vascular lesions of malignant nephrosclerosis. Several identified candidate genes were further assessed by RT-PCR and immunohistochemistry.

\section{Results}

\section{Malignant hypertension}

As described previously, the rat model of $2 \mathrm{~K} 1 \mathrm{C}$ was used to induce renovascular hypertension. Over a period of 35 days, only a part of rats spontaneously developed malignant hypertension (MH) after clipping of the left renal artery with a silver clip of $0.2 \mathrm{~mm}$ internal diameter [15]. $\mathrm{MH}$ animals were classified by significantly reduced postinterventional weight gain and the occurrence of fibrinoid necrosis and onion skin type lesions as characteristic vascular lesions in the contralateral kidney (supplementary Fig. 1) as described earlier [14]. Non-malignant hypertensive (NMH) individuals in contrast were hypertensive without developing characteristic renal vascular lesions and showed normal weight gain (supplementary table 1). In MH animals increased serum levels of creatinine, urea and aldosterone were found compared to NMH and sham (supplementary table 1). Serum creatinine in $\mathrm{MH}$ increased to levels comparable to those observed in models of glomerulonephritis or subtotal nephrectomy $[16,17]$, as did albuminuria (supplementary table 2). Mean arterial blood pressure (MAP) values were higher in $\mathrm{MH}$ compared to NMH, while MAP of both NMH and MH was significantly increased compared to sham animals (supplementary table 1). Systolic blood pressure values obtained by sequential tail cuff measurements from week 1 until week 5 after $2 \mathrm{~K} 1 \mathrm{C}$ revealed a trend towards higher pressure levels in MH beginning 1.5 weeks post intervention (supplementary Fig. 2). Relative left ventricular weight was increased in $\mathrm{MH}$ and NMH animals compared to sham but did not significantly differ between MH and NMH (supplementary table 1) although there were vascular lesions and microinfarctions in the myocardium of MH (supplementary Fig. 3).

\section{Renal gene expression patterns in malignant hypertension}

Global gene expression in the non-clipped right kidney was assessed in sham, $\mathrm{MH}$, and NMH animals using mRNAseq analysis [18]. To evaluate specific effects of malignant hypertension, differentially expressed genes in renal tissue were analyzed comparing MH and NMH animals. One thousand one hundred thirty-five genes showed a significantly differential expression (fold change $\leq 2$, fold change $\geq 2$, adjusted p-value $<0.01)$. Among them, 886 genes exclusively showed an expressional regulation in $\mathrm{MH}$ animals only (Fig. 1). Graphical representation of $\log 2$ fold change versus mean expression in $\mathrm{MH}$ and $\mathrm{NMH}$ animals indicated

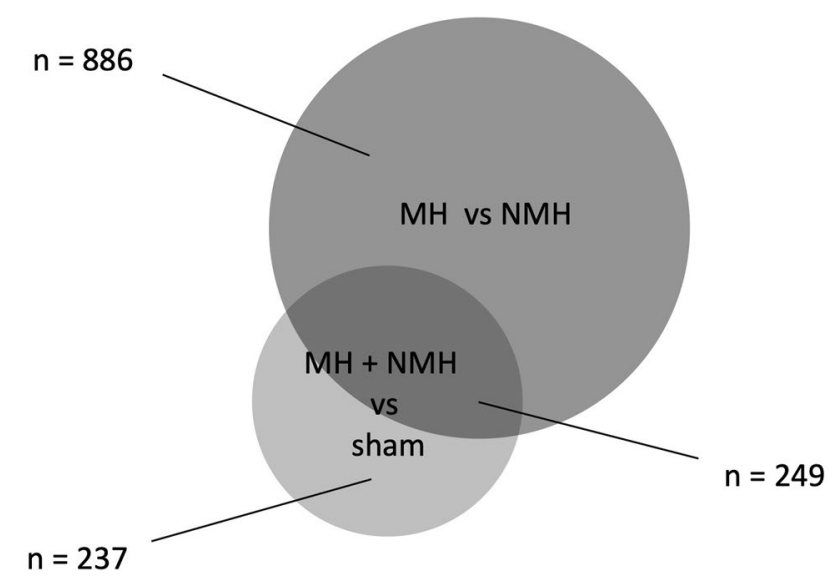

Fig. 1 Venn diagram showing the number of differentially expressed genes from RNA-seq analysis 


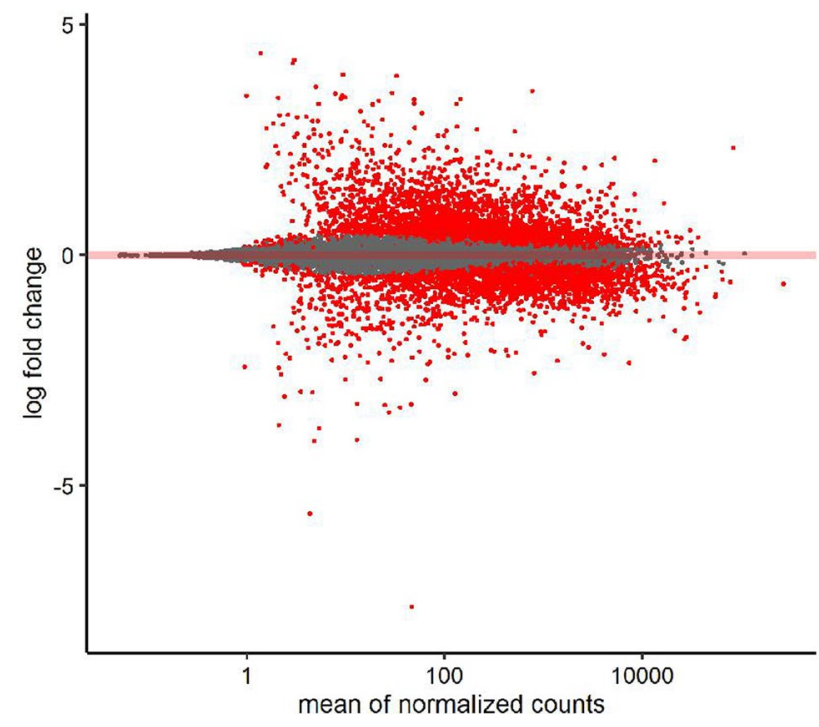

Fig. 2 MA plot. Scatterplot of $\log 2$ expression fold changes versus mean gene expression. Fold changes from highly variable genes are compressed using the apeglm approach from DESeq2 to aid with interpretation. Genes with significant expression differences (adjusted $p$-value $<0.01)$ are shown in red

that the majority of regulated genes were upregulated (Fig. 2). Further evaluation of RNA-seq data comparing MH and NMH animals showed 765 genes significantly upregulated and 370 genes significantly downregulated in $\mathrm{MH}$.

Principal component analysis (PCA) revealed a separated clustering of the three study groups (Fig. 3). This observation is also supported by selected heat maps, depicting the differential expression of target genes related to "glomerular

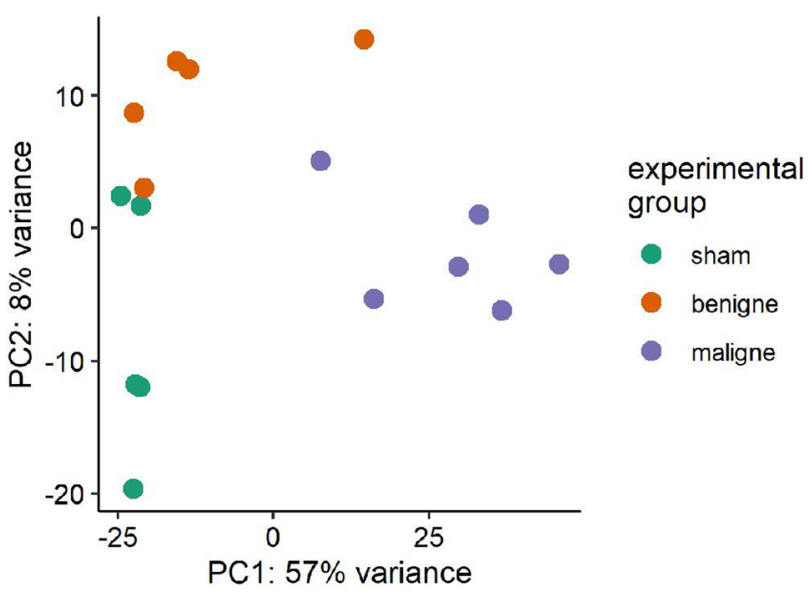

Fig. 3 Principal component analysis (PCA) of gene expression in the individual samples. The labeling of the axes indicates the percentage of total variance explained by each component. Due to the higher variance explained by the $\mathrm{PC} 1$, differences along the $\mathrm{x}$-axis are larger compared to differences along the y-axis. PC, principal component disease" (Fig. 4A), "vasculitis" (Fig. 4B), and "thrombosis" (Fig. 4C) (supplementary Fig. 4 shows the same data ordered by predetermined experimental group). These three topic areas were chosen because they reflect major sequelae of malignant hypertension in the kidney-elevated blood pressure induced glomerular and vascular changes and thrombotic microangiopathy.

\section{Inflammatory pathways}

Ingenuity pathway analysis (IPA, Qiagen) was used for further in silico network and pathway analysis of differentially expressed genes. Disease-specific comparison of MH and NMH animals revealed "inflammatory response" as the most significantly altered signaling network based on the associated number of differentially regulated genes (Table 1). Accordingly, IPA software identified the most relevant upstream regulators to belong to the group of proinflammatory molecular markers (Table 2).

Based on these findings, a further assessment of inflammatory cells in the kidney was performed. Using immunohistochemistry, more cytotoxic T-cells were found in the kidneys of MH animals compared to controls (Table 3, supplementary Fig. 5), while numbers of T-helper cells were only increased in NMH animals compared to controls (Table 3, supplementary Fig. 5). The local quantity of renal M1 macrophages was significantly higher in $\mathrm{MH}$ animals compared to NMH and sham animals (Table 3, supplementary Fig. 5). However, the number of M2 macrophages was increased only in the kidneys of $\mathrm{MH}$ animals compared to sham-controls (Table 3, supplementary Fig. 5). A significantly higher infiltration by MPO-positive cells was found in MH compared to NMH and sham (Table 3, Fig. 5). Macrophages as well as neutrophil granulocytes may be MPOpositive; stainings of serial sections for MPO and CD68 showed that at least part of the MPO-positive cells were CD68 negative (supplementary Fig. 6), suggesting infiltration of neutrophil granulocytes in MH. Fox-P3-positive regulatory $\mathrm{T}$ cells were increased in $\mathrm{MH}$ and $\mathrm{NMH}$ versus sham-operated controls, but there was no difference between $\mathrm{MH}$ and NMH, respectively (supplementary Fig. 7).

Renal expression levels of the chemokines CC-chemokine ligand 2 (CCL2), CC-chemokine ligand 7 (CCL7), and $\mathrm{C}-\mathrm{X}-\mathrm{C}$ motif chemokine ligand 6 (CXCL6) were significantly increased in the kidney of $\mathrm{MH}$ compared to $\mathrm{NMH}$ and sham animals (Table 3). CC-Chemokine ligand 3 (CCL3) expression was only increased in $\mathrm{MH}$ rats compared to controls. CC-chemokine ligand 5 (CCL5) and C-X-C motif chemokine ligand 3 (CXCL3) showed no induction under malignant hypertension (Table 3 ). The renal expression of $\mathrm{C}-\mathrm{C}$ chemokine receptor type 2 (CCR2), the receptor of CCL2 and CCL7, showed an increased expression in MH compared to sham but not to NMH (Table 3). 
A

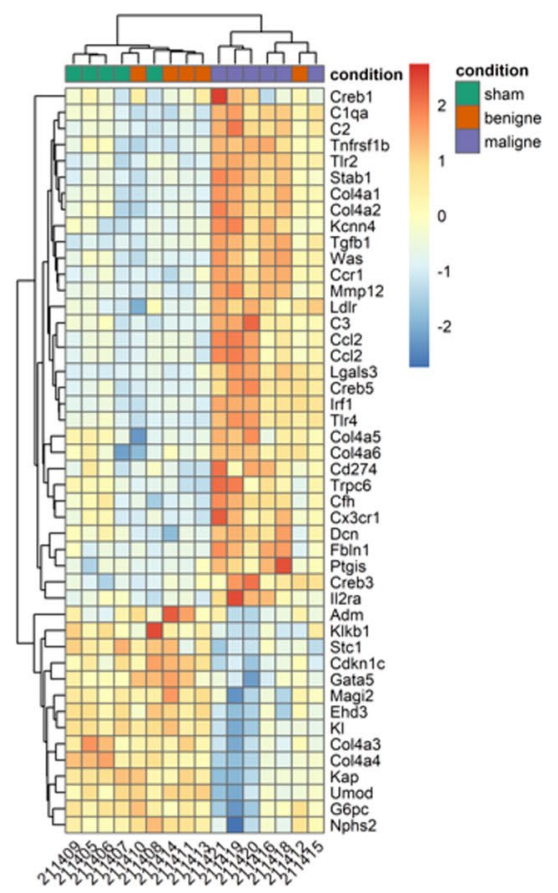

B

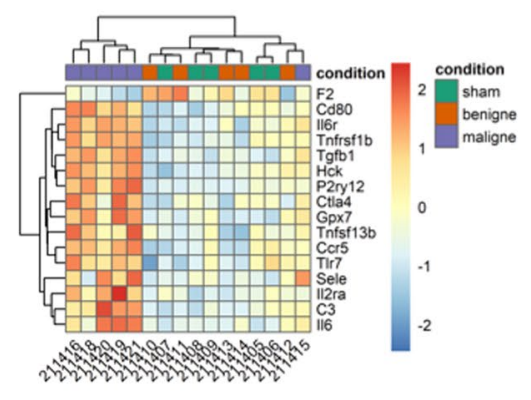

C

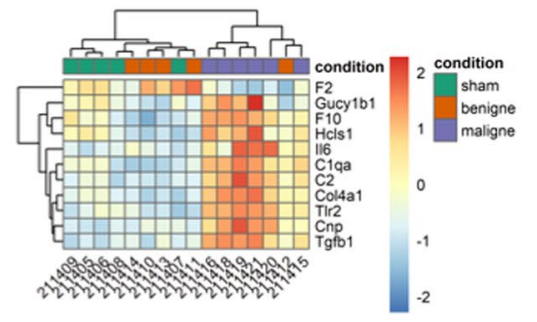

Fig. 4 Heat map analyses. Heat maps of normalized (rlog, DESeq2) expression values, centered and scaled by row. Clustering uses the Euclidean distance with complete linkage. A Heat map with genes

In the group of cytokines, interleukin-10 (Il-10), leukemia inhibitory factor (LIF), and tumor necrosis factor-alpha (TNF- $\alpha$ ) showed a significant expressional induction in $\mathrm{MH}$ compared to NMH and controls (Table 3). Interleukin-6 (Il6) and interleukin-17a (Il-17a) expressions were increased only in MH compared to sham. CD80, a costimulatory molecule, showed an induction of renal expression in the kidney of MH compared to NMH, while for its ligand CTLA4, only a trend towards higher expression levels in MH animals was observed (Table 3). Vascular cell adhesion protein 1 (VCAM-1) and intercellular adhesion molecule 1 (ICAM-1) showed higher renal expression levels in MH compared to sham (Table 3).

Pearson's correlation coefficient was used to quantify the association between selected molecular markers of

Table 1 Top 5 diseases and disorders

\begin{tabular}{lll}
\hline & $\boldsymbol{p}$-value range & $\begin{array}{l}\text { Number of } \\
\text { molecules }\end{array}$ \\
\hline Inflammatory response & $6,03 \mathrm{E}-13-2,02 \mathrm{E}-51$ & 412 \\
Endocrine system disorders & $7,15 \mathrm{E}-16-9,92 \mathrm{E}-47$ & 215 \\
Gastrointestinal disease & $2,28 \mathrm{E}-13-9,92 \mathrm{E}-47$ & 909 \\
Metabolic disease & $7,15 \mathrm{E}-16-9,92 \mathrm{E}-47$ & 236 \\
$\begin{array}{l}\text { Organismal injury and } \\
\text { abnormalities }\end{array}$ & $8,19 \mathrm{E}-13-9,92 \mathrm{E}-47$ & 973 \\
\hline
\end{tabular}

related to "glomerular disease"; B heat map with genes related to "vasculitis"; C heat map with genes related to "thrombosis"

inflammation and inflammatory cells (Table 4). CCL2 positively correlated with M1 and M2 macrophages. CCL7 only showed a positive correlation with M1 macrophages not with M2 macrophages. CXCL6 revealed a positive correlation with MPO-positive cells (Table 4).

A broad consistence was detected between RT-PCR and RNA-seq when comparing the expression changes of these candidate genes, except for CCL5 (Table 5).

\section{Complement system}

RNA-seq analysis revealed a significant expressional induction of the classical complement system signaling pathway in MH compared to NMH animals (Fig. 6). Certain components of the lectin and alternate complement cascades were also activated. Using RT-PCR, the expressional induction of C4b, C5aR1, and C6 was verified in the kidneys of MH in

Table 2 Top 5 upstream regulators

\begin{tabular}{ll}
\hline & $\boldsymbol{p}$-value \\
\hline TNF & $2,96 \mathrm{E}-57$ \\
TGFB1 & $8,88 \mathrm{E}-43$ \\
IFNG & $1,25 \mathrm{E}-40$ \\
IL1B & $2,07 \mathrm{E}-40$ \\
CSF2 & $5,48 \mathrm{E}-35$ \\
\hline
\end{tabular}


Table 3 Inflammatory cells, chemokines, and cytokines

\begin{tabular}{|c|c|c|c|}
\hline & Sham & NMH & MH \\
\hline \multicolumn{4}{|l|}{ Inflammatory cells } \\
\hline MPO-positive cells [cells/view] & $0.53 \pm 0.15$ & $0.69 \pm 0.15$ & $2.43 \pm 0.51 * \S$ \\
\hline M1 macrophages [CD68-positive cells/view] & $5.7 \pm 0.53$ & $8.87 \pm 0.82 *$ & $14,66 \pm 1.44 * \S$ \\
\hline M2 macrophages [Cd163-positive cells/view] & $0.09 \pm 0.04$ & $0.58 \pm 0.24$ & $1.19 \pm 0.3 *$ \\
\hline T-helper cells [Cd4-positive cells/view] & $11.56 \pm 3.37$ & $88.15 \pm 22.7 *$ & $57.11 \pm 13.45$ \\
\hline Cytotoxic T-cells [Cd8a-positive cells/view] & $3.12 \pm 0.38$ & $4.2 \pm 0.45$ & $5.46 \pm 0.47^{*}$ \\
\hline \multicolumn{4}{|l|}{ Chemokines } \\
\hline CCL2 [fold induction] & $1.00 \pm 0.23$ & $5.85 \pm 1.46$ & $11.48 \pm 1.33 * \S$ \\
\hline CCL3 [fold induction] & $1.00 \pm 0.14$ & $2.15 \pm 0.5$ & $2.70 \pm 0.31 *$ \\
\hline CCL5 [fold induction] & $1.00 \pm 0.32$ & $1.66 \pm 0.23$ & $2.24 \pm 0.43$ \\
\hline CCL7 [fold induction] & $1.00 \pm 0.23$ & $4.50 \pm 0.65^{*}$ & $7.78 \pm 0.95^{* \S}$ \\
\hline CXCL3 [fold induction] & $1.00 \pm 0,32$ & $4,85 \pm 1,1$ & $12,99 \pm 5,7$ \\
\hline CXCL6 [fold induction] & $1.00 \pm 0.32$ & $14.38 \pm 5.33$ & $56.74 \pm 13.43 * 8$ \\
\hline CXCL8 [fold induction] & $1.00 \pm 0.18$ & $1.58 \pm 0.36$ & $2.52 \pm 0.57$ \\
\hline CCR2 [fold induction] & $1.00 \pm 0.14$ & $6.54 \pm 2.62$ & $11.7 \pm 1.9^{*}$ \\
\hline \multicolumn{4}{|l|}{ Cytokines } \\
\hline IL-6 [fold induction] & $1.00 \pm 0.24$ & $12.67 \pm 2.66^{*}$ & $19.24 \pm 2.3^{*}$ \\
\hline IL-10 [fold induction] & $1.00 \pm 0.17$ & $2.62 \pm 0.47$ & $5.90 \pm 0.71 * \S$ \\
\hline IL-17a [fold induction] & $1.00 \pm 0.12$ & $5.40 \pm 1.94$ & $26.85 \pm 10.5^{*}$ \\
\hline LIF [fold induction] & $1.00 \pm 0.16$ & $8.51 \pm 1.79 *$ & $19.16 \pm 2.26^{* \S}$ \\
\hline TNF- $\alpha$ [fold induction] & $1.00 \pm 0.21$ & $2.54 \pm 0.42 *$ & $4.00 \pm 0.35^{* \S}$ \\
\hline \multicolumn{4}{|l|}{ Costimulatory molecules } \\
\hline CD80 [fold induction] & $1.00 \pm 0.18$ & $4.83 \pm 1.25$ & $10.9 \pm 2.27 * \S$ \\
\hline CTLA4 [fold induction] & $1.00 \pm 0.22$ & $4.47 \pm 1.29$ & $13.34 \pm 2.79$ \\
\hline \multicolumn{4}{|l|}{ Adhesion molecules } \\
\hline ICAM-1 [fold induction] & $1.00 \pm 0.17$ & $5.57 \pm 1.63$ & $9.73 \pm 0.56^{*}$ \\
\hline VCAM-1 [fold induction] & $1.00 \pm 0.24$ & $2.84 \pm 0.62$ & $4.08 \pm 0.31 *$ \\
\hline
\end{tabular}

${ }^{*} p$-value $<0.05$ versus sham, $\S p$-value $<0.05$ versus $\mathrm{NMH}$ comparison to NMH and sham. C3 and C3aR1 expression was found elevated in MH only compared to sham (Table 6). The expression of C3 was correlated with other complement components as well as with markers of infiltration and kidney injury but not with the level of blood pressure (supplementary table 3 ).

Using immunohistochemistry, we detected that $\mathrm{MH}$ is accompanied by a significantly higher number of $\mathrm{C} 1 \mathrm{q}$ and $\mathrm{C} 3 \mathrm{c}$ positive glomeruli compared to $\mathrm{NMH}$ and sham (Fig. 7). Staining for C1q, C3c, and C3d was also present in damaged preglomerular arterioles in MH (Fig. 8). Immunofluorescence demonstrated that $\mathrm{C} 3 \mathrm{~d}$ was preferentially localized in areas where endothelial staining was lost, both in glomeruli and arterioles (Fig. 8).

\section{Discussion}

Malignant hypertension is a life-threatening disease. Its pathogenic background is still unclear, especially the factors which determine the development towards malignant or non-malignant hypertension. Apart from that, the transition from non-malignant to malignant hypertension might serve as a model to identify pathways leading to more extensive target organ damage in situations other than malignant hypertension.

In this context, we systematically compared gene expression patterns in our rat model of induced renovascular hypertension leading to the spontaneous development of malignant hypertension in some but not all animals, using RNA-seq. The objective was to detect candidate genes and pathways exclusively regulated under malignant hypertension, compared with non-malignant hypertensive rats. We focused on gene expression in the contralateral (not the clipped) kidney because this kidney displays the characteristic vascular lesions of malignant hypertension. We observed the most prominent upregulation of gene expression in functional pathways related to processes of inflammation and cell infiltration. This result did not come as a surprise, as an inflammatory response in kidneys exposed to high blood pressure has been well recognized for decades in this animal model [13,19] as well as in other models [20, 
Fig. 5 Infiltration of MPOpositive cells into kidney tissue. A Exemplary photomicrographs of renal sections stained for myeloperoxidase (MPO). Bar represents $100 \mu \mathrm{m}$. B Evaluation of MPO-positive cell counts. Sham, sham-operated animals $(n=9)$; NMH, non-malignant hypertension $(n=13)$; MH, malignant hypertension $(n=11)$. Data are means \pm standard error of the mean, statistical test oneway ANOVA, Bonferroni post hoc test. $* p<0.05$ vs. sham, $\S$ $p<0.05$ vs. NMH
A
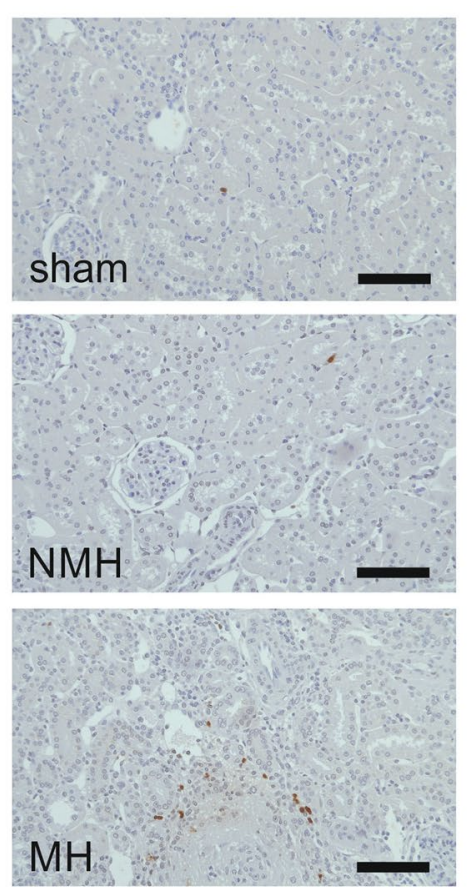

B

MPO-positive cells

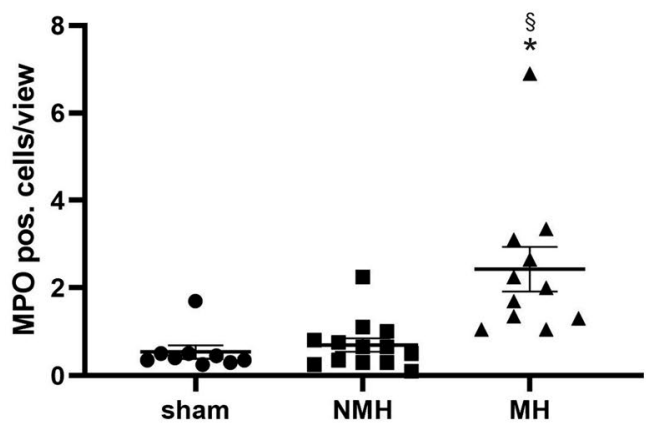

21]. Nevertheless, our data point to a number of distinct pathways, which are upregulated in malignant hypertension.

Perhaps the most intriguing finding was the increased local expression of pathway components associated with complement activation. The similarity of renal vascular lesions observed in malignant hypertension to the ones seen in complement-mediated hemolytic-uremic syndrome has often been noted [22], and distinguishing between both diseases can be challenging in the clinical setting. Timmermans et al. [23] have reported that complement abnormalities may underlie at least a subset of patients with malignant hypertension, but this finding has not been corroborated by other authors [24]. In this regard, our model may be of interest because we found both complement activation and vascular lesions suggestive of thrombotic microangiopathy

Table 4 Correlation of selected molecular markers of inflammation and inflammatory cells

\begin{tabular}{llc}
\hline & $\boldsymbol{r}$ & $\boldsymbol{p}$-value \\
\hline $\begin{array}{l}\text { CCL2 (mRNA expression) vs. M1 macrophages } \\
\text { (cells/view) }\end{array}$ & 0.82 & $<0.001$ \\
$\begin{array}{l}\text { CCL2 (mRNA expression) vs. M2 macrophages } \\
\text { (cells/view) }\end{array}$ & 0.80 & 0.01 \\
$\begin{array}{l}\text { CCL7 (mRNA expression) vs. M1 macrophages } \\
\text { (cells/view) }\end{array}$ & 0.83 & $<0.001$ \\
$\begin{array}{l}\text { CCL7 (mRNA expression) vs. M2 macrophages } \\
\text { (cells/view) }\end{array}$ & 0.43 & 0.25 \\
$\begin{array}{l}\text { CXCL6 (mRNA expression) vs. MPO-positive } \\
\text { cells (cells/view) }\end{array}$ & 0.83 & $<0.001$ \\
\hline
\end{tabular}

$r=$ Pearson's correlation coefficient $\mathrm{r}$

Statistical significance was defined as $p$-value $<0.05$ despite the absence of other triggers for complement activation except hypertension. Because the functional role of renal expression of complement factors relative to serumderived factors (which we did not measure) is unknown, and as the complement cascade is characterized by numerous

Table 5 Overview of ratios for the relative expression changes in both analytic procedures (PCR and RNA-seq)

\begin{tabular}{lll}
\hline Gene & Ratio & \\
\cline { 2 - 3 } & PCR (Mal vs. NMH) & $\begin{array}{l}\text { RNA-seq } \\
\text { (Mal vs. } \\
\text { NMH) }\end{array}$ \\
\hline C3 & & 3.62 \\
C3aR1 & 2.12 & 3.72 \\
C4b & 1.56 & 6.86 \\
C5aR1 & 3.52 & 3.09 \\
C6 & 2.95 & 4.37 \\
CCL2 & 3.61 & 3.45 \\
CCL3 & 1.96 & 1.49 \\
CCL5 & 1.26 & 0.65 \\
CCL7 & 1.35 & 2.78 \\
CXCL3 & 1.73 & 9.86 \\
IL-6 & 2.68 & 3.5 \\
IL-10 & 1.52 & 7.31 \\
IL-17a & 2.25 & 5.38 \\
LIF & 4.97 & 2.96 \\
CD80 & 2.25 & 2.61 \\
CTLA4 & 2.26 & 3.36 \\
ICAM-1 & 2.98 & 2.20 \\
VCAM-1 & 1.75 & 1.77 \\
\hline
\end{tabular}



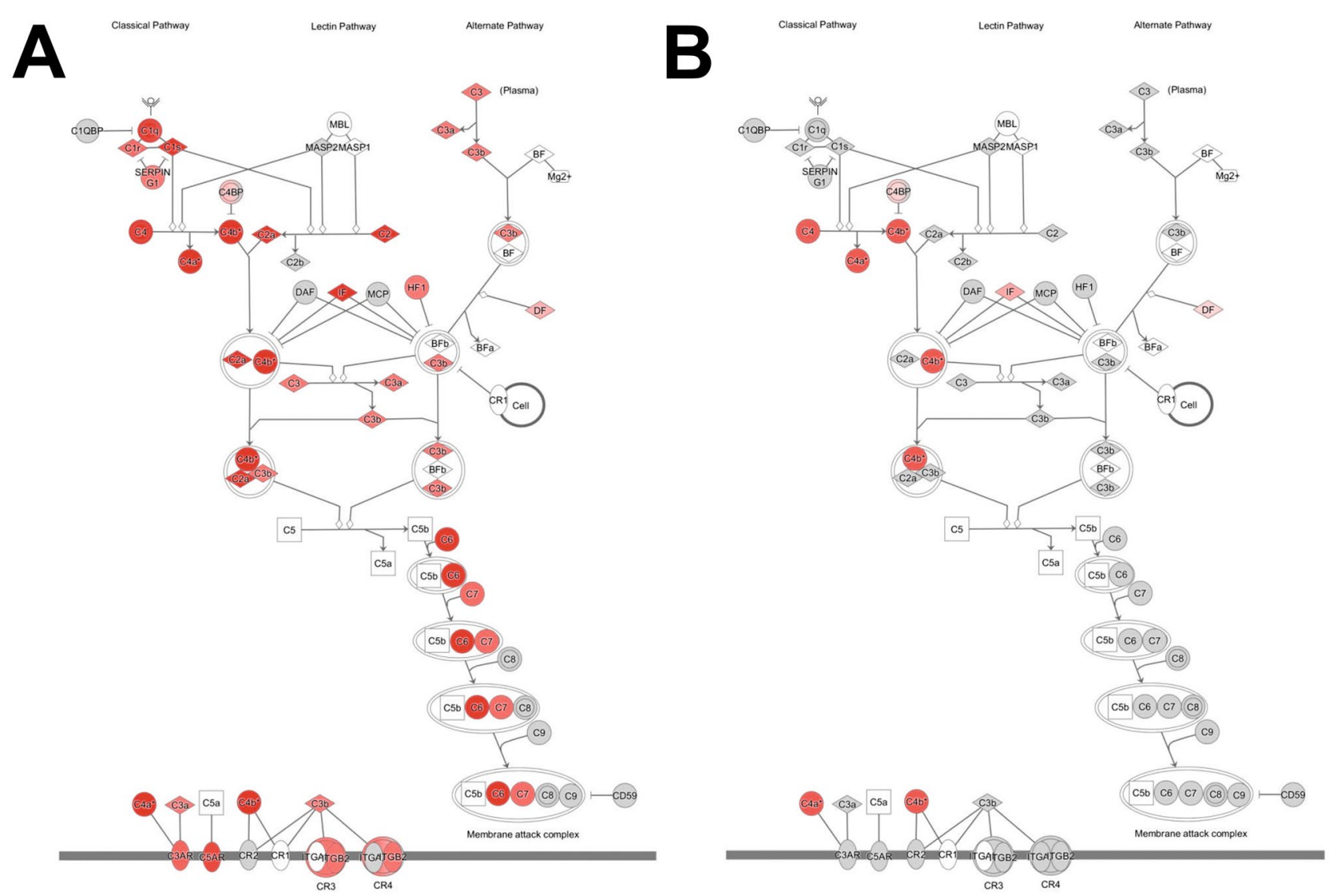

Fig. 6 Schematic drawing of the complement cascade derived from ingenuity pathway analysis. All upregulated genes are depicted in red color. A MH vs. sham, B NMH vs. sham

post-translational interactions of its components, we determined the renal deposition of factors $\mathrm{C} 1$ and $\mathrm{C} 3$ by immunohistochemistry. Both components were present in glomeruli and preglomerular vessels of malignant hypertensive rats.

Our findings contrast with some animals studies including the report of Cole et al. [25] who did not find an effect of complement $\mathrm{C} 3$ deficiency on angiotensin II-induced hypertension and hypertrophy in mice. On the other hand, Ruan et al. [26] described a crucial role of C5a for the vascular inflammation in mouse DOCA-salt hypertension, and Negishi et al. [27] reported that $\mathrm{C} 3$ contributes to salt-sensitive hypertension in spontaneously hypertensive rats. Finally,

Table 6 mRNA expression of selected complement factors

\begin{tabular}{lllc}
\hline & Sham & NMH & MH \\
\hline C3 [fold induction] & $1.00 \pm 0.24$ & $5.58 \pm 1.71$ & $11.84 \pm 2.75^{*}$ \\
C3aR1 [fold induction] & $1.00 \pm 0.22$ & $2.87 \pm 0.58$ & $4.48 \pm 0.90^{*}$ \\
C4b [fold induction] & $1.00 \pm 0.14$ & $8.85 \pm 3.63$ & $31.17 \pm 7.10^{*}$ \\
C5aR1 [fold induction] & $1.00 \pm 0.21$ & $3.46 \pm 0.85$ & $10.21 \pm 2.25^{*}$ \\
C6 [fold induction] & $1.00 \pm 0.34$ & $4.63 \pm 1.46$ & $16,72 \pm 5.10^{*}$ \\
\hline
\end{tabular}

${ }^{*} p$-value $<0.05$ versus sham, $\S p$-value $<0.05$ versus $\mathrm{NMH}$ the group of Wenzel et al. [28, 29] described a functional role of the complement receptor C5aR1 for the development of kidney injury in a mouse model of angiotensin IIinduced hypertension. Thus, the role of complement factors for hypertensive target organ damage remains controversial. Our results do not permit to distinguish between local complement activation and trapping of complement factors, but the localization of these factors, and their association with serious kidney injury, is compatible with a contribution of complement activity to the most severe forms of vascular and glomerular damage in malignant hypertension.

A number of chemokines known to attract mononuclear cells were induced by renovascular hypertension and even more increased in the malignant form of the disease, notably CCL2 and CCL7. This observation as well as the corresponding increase of $\mathrm{M} 1$ macrophage infiltration was to be expected from previous reports from the same model [13]. Others have previously shown that blockade or deficiency of CCL2 ameliorates mononuclear cell infiltration and target organ damage in renovascular or other forms of hypertension [30, 31]. These data are certainly compatible with a role for macrophage infiltration in the development of malignant hypertension, but the parallel increase of M2 
a $\quad$ C1q
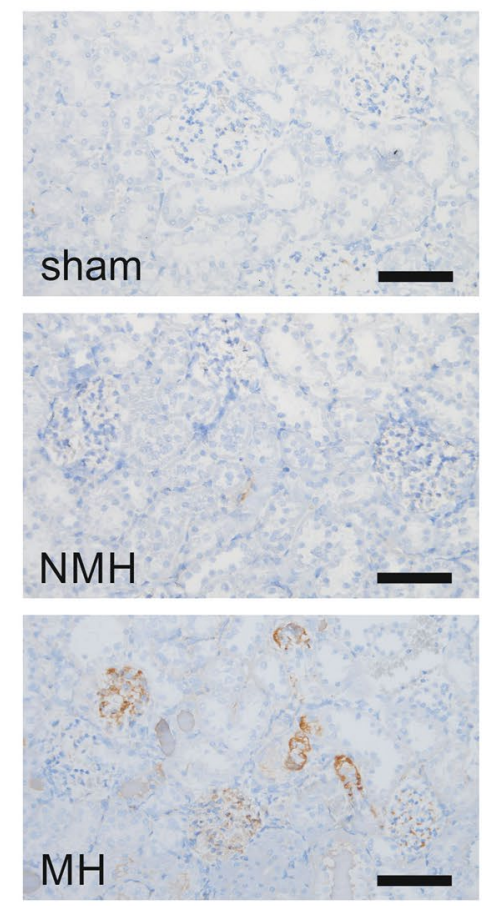

$\mathrm{C} 3 \mathrm{c}$
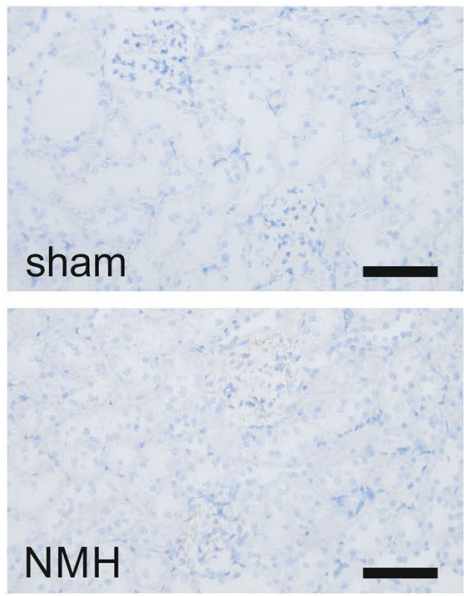

$\mathrm{MH}$
B

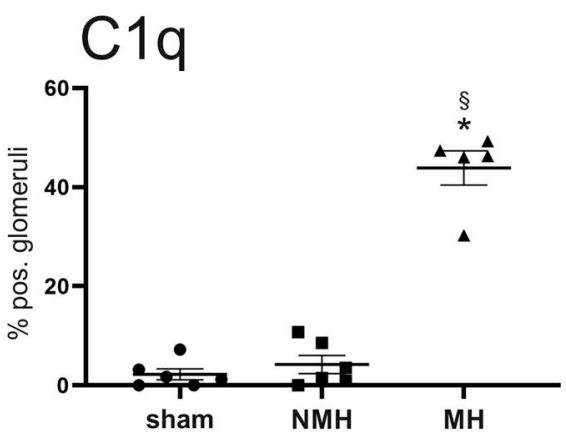

$\mathrm{C} 3 \mathrm{c}$

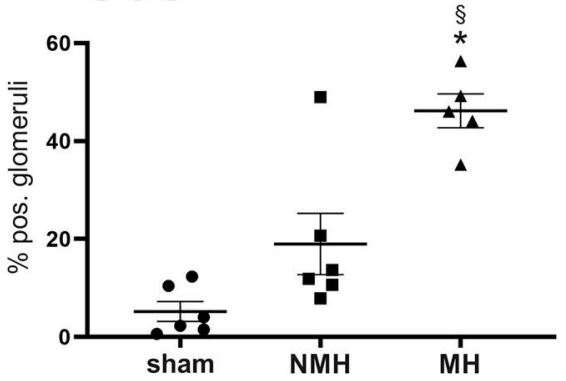

Fig. 7 Components of the complement system ( $\mathrm{C} 1 \mathrm{q}$ and $\mathrm{C} 3 \mathrm{c}$ ) detected in kidney tissue. A Exemplary photomicrographs of renal sections stained for C1q or C3c. Bar represents $100 \mu \mathrm{m}$. B evaluation of glomeruli stained positive for $\mathrm{C} 1 \mathrm{q}$ or $\mathrm{C} 3 \mathrm{c}$. Sham, sham-operated animals ( $n=6)$; NMH, non-malignant hypertension $(n=6)$; $\mathrm{MH}$, malignant hypertension $(n=5)$. Data are means \pm standard error of the mean. ${ }^{*} p<0.05$ vs. sham, $\S p<0.05$ vs. NMH

prevented the development of experimental hypertension in mice [36]. We are not aware of further studies addressing the role of co-stimulation for target organ injury in established hypertension. One might speculate that the enhanced expression of CTLA-4 and CD80 in malignant hypertension could point to an ongoing specific immune response.

Further, we noted a markedly increased expression of the chemokine CXCL6, which is known to attract neutrophil granulocytes, accompanied by increased expression of E-selectin [37]. Therefore, we attempted to assess granulocyte infiltration by staining for MPO; MPO-positive cells were observed exclusively in kidneys from animals with malignant hypertension. However, some macrophages are also MPOpositive; and we could ultimately not resolve which part of MPO-positive cells were granulocytes versus macrophages. Most previous reports on the role of granulocytes in hypertension focus on circulating neutrophils [38], and neutrophil granulocytes can damage endothelial cells in vitro [39, 40].

Our study has several limitations. First, the study groups $\mathrm{MH}$ and NMH might also be regarded as two extremes of a continuous spectrum rather than two distinct clinical courses. Data obtained from PCA as well as the fact that the same 
Fig. 8 Exemplary photomicrographs of renal sections stained for $\mathrm{C} 1 \mathrm{q}$ or $\mathrm{C} 3 \mathrm{c}$. Arrows point to stained vascular structures. Fluorescent stainings to localize complement deposition: Complement C3d (red) was costained with $\alpha$-smooth muscle actin (white, detecting vascular smooth muscle cells) and endothelium of blood vessels (green, aminopeptidase $\mathrm{P}$, see reference 45). Bar represents $50 \mu \mathrm{m}$
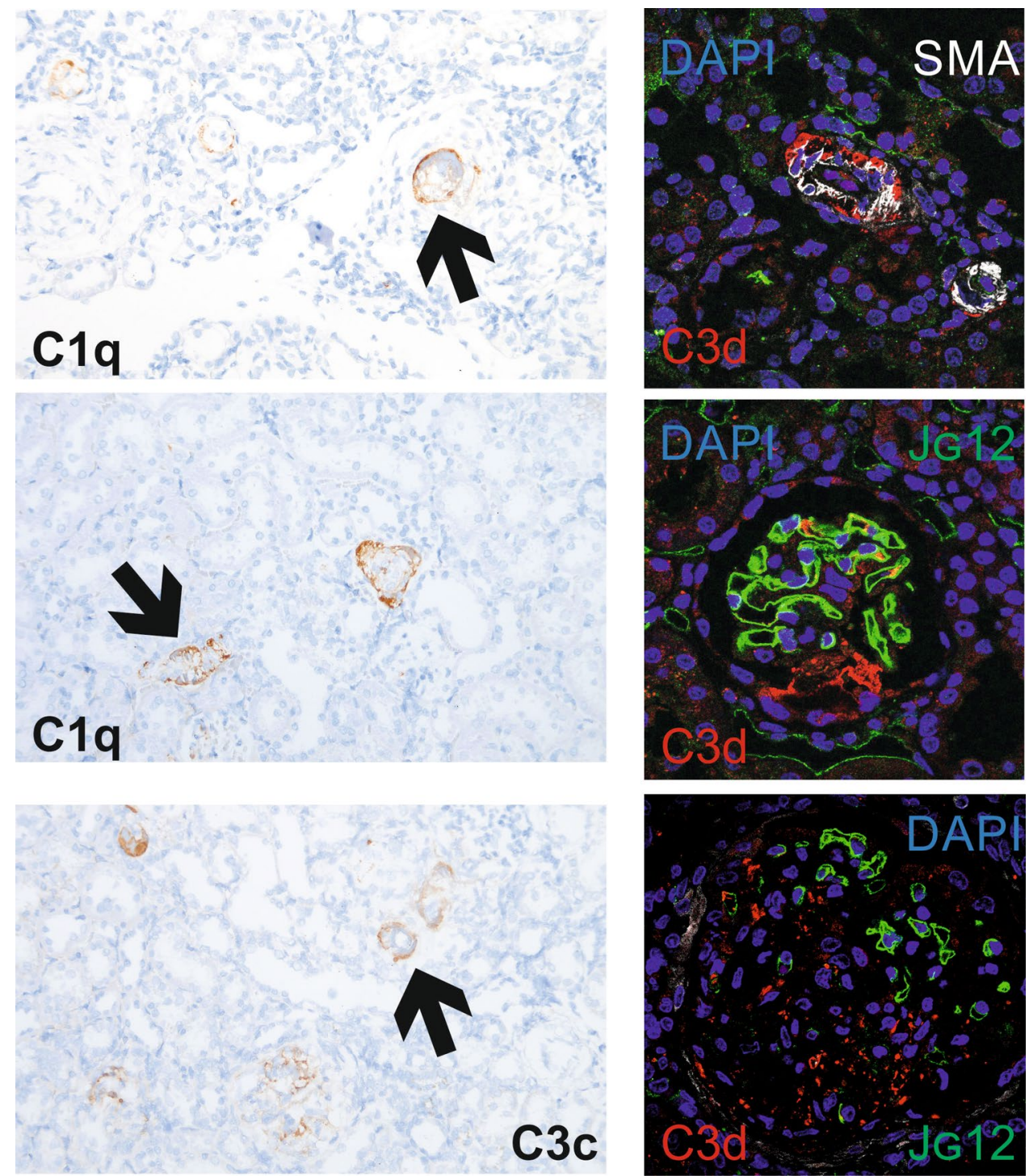

intervention by $2 \mathrm{~K} 1 \mathrm{C}$ induces significantly different courses of pathology supports the classification of $\mathrm{MH}$ and $\mathrm{NMH}$ animals as two distinct categories. Furthermore, comparisons between two extremes of a spectrum might still point to pathways associated with more severe hypertensive damage. Second, renal alterations in $\mathrm{MH}$ animals were only assessed at one time point. This does not allow to discriminate if the observed alterations are cause or effect of malignant hypertension. Our data are fully compatible with the notion of a threshold pressure which might trigger the observed transcriptional changes [5]. Blood pressure was measured by tail cuff during the course and intraarterially at the termination of the experiment, but not by radiotelemetry which might have provided more information. Data obtained by RNA-seq were confirmed by RT-PCR and immunohistochemistry, but no functional tests were performed. These tests will be necessary to clarify in further studies the pathogenic link and mechanistic background of renal damage and malignant hypertension. Further, end-organ damage under malignant hypertension was only examined in the kidney not in other organs also affected by malignant hypertension, e.g., the brain and heart. Finally, we performed bulk RNA-seq with RNA extracted from renal cortical tissue. Single-cell RNA sequencing which was not available to us might have provided more information on the cell infiltrate as well as on the question which pathways are activated in which specific cell type. Conversely, our focus on kidney cortical tissue will miss differential gene expression in kidney medulla. Nevertheless, our data point to potential therapeutic targets for malignant hypertension, especially with regard to the complement system. 


\section{Material and methods}

\section{Induction of renovascular hypertension}

All procedures performed on animals were done in compliance with the DIRECTIVE 2010/63/EU of the European Parliament and were approved by the local government authorities (Regierung of Mittelfranken, AZ54-2532.1-51/12). Animal experiments were reported with adherence to the ARRIVE guidelines [41].

Rats were housed in a room maintained at $22 \pm 2{ }^{\circ} \mathrm{C}$, exposed to a $12 \mathrm{~h}$ dark/light cycle. The animals were allowed unlimited access to chow (\#1320, Altromin, Lage, Germany) and tap water. Two-kidney, one-clip renovascular hypertension $(2 \mathrm{~K} 1 \mathrm{C})$ was induced in male Sprague-Dawley rats (Charles River, Sulzfeld, Germany) weighing 150-170 g by placing a silver clip of $0.2 \mathrm{~mm}$ internal diameter around the left renal artery through a flank incision under isoflurane anesthesia as previously described [15]. Control animals underwent sham operation without placement of the clip. Analgesia with subcutaneous buprenorphine injections was provided post-operatively in all animals and as needed later on.

\section{Experimental groups}

Five weeks after clipping of the left renal artery, the experiment was terminated, animals were weighted, and renal tissue was studied for the presence of onion skin lesions and fibrinoid necrosis in all contralateral kidneys exposed to high blood pressure. Thirteen control animals underwent sham operation (sham). Fourteen animals were defined as malignant hypertensive $(\mathrm{MH})$ and 13 as non-malignant hypertensive (NMH). The criteria used for the definition of malignant hypertension in this study (weight loss and characteristic vascular lesions) are described in detail elsewhere [14].

\section{Blood pressure measurements and determination of serum markers}

Procedures of blood pressure measurements were described previously [14, 42]. In short, systolic blood pressure values were obtained by tail cuff measurements in trained rats $1,1.5,2,3,4$, and 5 weeks after $2 \mathrm{~K} 1 \mathrm{C}$ using a peripheral blood pressure monitoring system (TSE Technical Scientific Equipment GmbH, Bad Homburg, Germany). At the end of the experiment, femoral artery catheters were implanted under isoflurane anesthesia for invasive blood pressure measurements. Measurements were performed in conscious animals via transducers connected to a polygraph (Hellige, Freiburg, Germany). Blood samples with a total volume of $2 \mathrm{ml}$ were collected immediately before euthanasia. Serum creatinine, urea, and aldosterone were analyzed using the automatic analyzer Integra 800 (Roche Diagnostics, Mannheim, Germany).

\section{Tissue preparation and histological analysis}

After organ weighing, kidneys were decapsulated. Both poles of each kidney were immediately snap frozen on liquid nitrogen for RNA extraction. One slice of the kidney was snap frozen for protein isolation, while another slice of the remaining kidney was put in Methyl Carnoy's fixative (60\% methanol, $30 \%$ chloroform, and $10 \%$ glacial acetic acid) for fixation. Paraffin-embedded tissue was sectioned and stained with periodic acid Schiff's (PAS) reagent for detection of onion skin lesions and fibrinoid necrosis.

\section{RNA isolation}

RNA was isolated from tissue samples after homogenization with a disperser (T10 basic Ultra-Turrax; IKA, Staufen, Germany) using the RNeasy Fibrous Tissue Midi Kit (Qiagen, Hilden, Germany). In this procedure, Proteinase K was used as well as DNase to remove genomic DNA. The entire process was carried out according to the manufacturer's instructions.

\section{Whole transcriptome analysis (RNA-seq)}

As reported previously, quality of isolated RNA samples was determined using the Agilent 2100 Bioanalyzer equipped with an Agilent RNA 6000 Nano kit and related software (Agilent, Santa Clara, CA) [43]. RNA integrity number (RIN) values of $\geq 5$ were deemed suitable for analysis [44]. The RIN values of the samples were in a range from 6.5 to 10.5 .

RNA-seq was performed in MH $(n=6), \mathrm{NMH}(n=5)$, and sham animals $(n=5)$. Sequencing libraries were generated from 0.5 ug high-quality RNA using the TruSeq Stranded mRNA Kit (Illumina, San Diego, USA) according to the manufacturer's instructions. Libraries were sequenced on a HiSeq 2500 platform (Illumina, San Diego, USA) as $101 \mathrm{bp}$ single-end reads to a depth of at least 25 million reads. Reads were converted to FASTQ format while masking adapter sequences (bcl2fastq v2.17.1.4, Illumina, San Diego, USA). Sequences mapping to rRNA, tRNA, mtRNA, and transposons were removed by alignment against a custom reference list (bwa v0.7.14, samtools v1.8). Remaining reads were mapped to the Rattus norvegicus reference genome Rnor 6.0, Ensembl gene annotation 93, using a splice-aware aligner (STAR v2.5.4a) and quantified as reads per gene while excluding exons shared between more than one gene (subread v1.5.3). Based on this quantification, differentially 
expressed genes were determined using the negative binomial model as implemented in DESeq2 (DESeq2 v1.20.0, $\mathrm{R} v 3.5 .0$ ). Analysis was performed in the following groups: $\mathrm{MH}$ vs. $\mathrm{NMH}, \mathrm{NMH}$ vs. sham, $\mathrm{MH}$ vs. [NMH + s ham], and $[\mathrm{MH}+\mathrm{NMH}]$ vs. sham. Results from significance tests were corrected for multiple testing (Benjamini-Hochberg).

Raw data for RNA-seq are publicly available in the Gene expression Omnibus (GEO, NCBI) repository under the accession number (pending).

\section{Network and pathway analysis}

In silico network and pathway analysis was performed using Ingenuity Pathway Analysis software, Version 52,912,811 (Qiagen, Hilden, Germany). Differentially expressed genes with $\log 2$ fold change (LFC) $> \pm 2$ and a corrected $p$ value $<0.01$ were analyzed. By the comparison with the current Ingenuity knowledge base significantly altered networks, upstream regulators and central candidate genes were extracted.

\section{Immunohistochemistry}

Tissue was processed as described previously [14]. In summary, three micron sections of renal tissue were cut with a Leitz SM 2000 R microtome (Leica Instruments, Nussloch, Germany). Endogenous peroxidase activity was blocked with $3 \% \mathrm{H} 2 \mathrm{O} 2$ in methanol for $20 \mathrm{~min}$ at room temperature. Antigen retrieval was performed using Target Retrieval Solution (TRS) (DAKO, Hamburg, Germany). For the primary antibody, an overnight incubation at $4{ }^{\circ} \mathrm{C}$ was chosen. Secondary antibodies were incubated for $2 \mathrm{~h}$ at room temperature. Antibodies against CD68 (ED1; AbD Serotec, Kidlington; UK 1:250), myeloperoxidase (MPO) (Abcam, Cambridge, UK; 1:50), CD3 (Abcam, Cambridge, UK; 1:50), CD4 (Cell signaling, Danvers, Massachusetts, USA; 1:50), CD8a (Abcam, Cambridge, UK; 1:50), CD163 (Abcam, Cambridge, UK; 1:50), C1q (Dako, Glostrup, Denmark; 1:75,000), and C3c (Dako, Glostrup, Denmark; $1: 75,000)$ were used. Infiltration by inflammatory cells was assessed after staining with CD68 (M1 macrophages), MPO (neutrophil granulocytes, some macrophages), CD3 (T-lymphocytes), FoxP3 (regulatory T-cells), CD4 (T-helper cells), CD8a (cytotoxic T-cells), and CD163 (M2 macrophages) by counting the number of positive cells in 20 medium-power views (magnification $\times 200$ on a Leitz microscope). Furthermore, in each kidney, 100-200 glomeruli were counted, and the number of $\mathrm{C} 1 \mathrm{q}$ and $\mathrm{C} 3 \mathrm{c}$ positive glomeruli was expressed as a percentage of the total number of glomeruli counted. All antibodies were used on paraffin-embedded tissue sections. For immunofluorescence stainings antibodies to $\alpha$-smooth muscle actin (DAKO, Hamburg, Germany), aminopeptidase P (Invitrogen, Karlruhe, Germany) [45] and C3d (Abcam, Cambridge, UK) were applied, followed by secondary fluorescent antibodies: goat anti-mouse $\operatorname{IgG} 1$ conjugated with Alexa Fluor 488 (Dianova, Hamburg, Germany) and goat anti-mouse IgG2a conjugated with Alexa Fluor 633 (Life technologies GmbH, Darmstadt, Germany); sections were covered with autofluorescence quenching kit TrueView (Vector Laboratories, Burlingame, CA, USA) and analyzed using a confocal laser scanning microscope (LSM710) and ZEN software (both Zeiss, Oberkochen, Germany) All histological evaluations were done by a single investigator blinded to the group assignment.

\section{Real-time polymerase chain reaction (PCR) analyses}

Renal and myocardial tissue was homogenized in RLT buffer reagent (Qiagen, Hilden, Germany) with an ultraturrax for $30 \mathrm{~s}$, total RNA was extracted from homogenates by RNeasy Minicolumns (Qiagen) according to the manufacturer's protocol, and real-time RT-PCR was performed. First-strand cDNA was synthesized with TaqMan reverse transcription reagents (Applied Biosystems, Darmstadt, Germany) using random hexamers as primers. Reactions without Multiscribe reverse transcriptase were used as negative controls for genomic DNA contamination. PCR was performed with an ABI PRISM 7000 Sequence Detector System and TaqMan or SYBR Green Universal PCR Master Mix (Applied Biosystems), as described previously [42]. All samples were run in triplicates. Specific mRNA levels in hypertensive animals relative to sham-operated controls were calculated and normalized to a housekeeping gene (18S) with the $\Delta-\Delta-\mathrm{C}_{\mathrm{T}}$ method as specified by the manufacturer (http://www3.appliedbiosystems.com/cms/ groups/mcb_support/documents/generaldocuments/cms_ 040980.pdf). Primer pairs used for experiments are shown in supplementary table 4 .

\section{Statistics}

Data are expressed as means \pm standard error of the mean (SEM). Normality was tested using the Shapiro-Wilk test. Subsequently, to assess differences between sham, NMH, and $\mathrm{MH}$ animals, one-way analysis of variance (one-way ANOVA), followed by Bonferroni post hoc test or, where appropriate, Kruskal-Wallis, followed by Dunn's test, was performed using IBM SPSS 21 (SPSS Inc. Chicago, IL, USA). Results were considered significant at $p<0.05$. Pearson correlations were used to assess associations between selected molecular markers of inflammation and inflammatory cells. Strength of Pearson's correlations was graded according to the following pattern: $r=0.0-0.19$ "very weak," $r=0.2-0.39$ "weak," $r=0.4-0.59$ "moderate," $r=0.6-0.79$ "strong," and $r=0.8-1.0$ "very strong." Statistical significance was set at $p$-values $<0.05$ [46]. 


\section{Data availability statement}

Raw data for RNA-seq supporting this study are publicly available in the Gene expression Omnibus (GEO, NCBI) repository at https://www.ncbi.nlm.nih.gov/geo/query/acc. cgi?acc $=$ GSE154019.

Supplementary Information The online version contains supplementary material available at https://doi.org/10.1007/s00109-021-02133-8.

Acknowledgements The authors acknowledge the technical assistance of Miroslava Kupraszewicz-Hutzler and Rainer Wachtveitl.

Author contribution $\mathrm{CM}-\mathrm{C}, \mathrm{AH}$, and $\mathrm{KFH}$ designed the study, interpreted the data, and drafted the manuscript. KA, CD, FBF, JW, and MS contributed to the design of the study and critically revised the paper. $\mathrm{NC}$ performed the surgical procedures and analyzed the data. ABE and $\mathrm{PK}$ performed the whole transcriptome analysis and supported the analysis and interpretation of the data.

Funding Open Access funding enabled and organized by Projekt DEAL. This study was funded by Deutsche Forschungsgemeinschaft (SFB 1350, TP C02 and HI 510/10-1); Fischer Business Technology $\mathrm{GmbH}$, Munich, Germany; and Doktor Robert Pfleger-Stiftung, Bamberg, Germany.

\section{Declarations}

Ethics approval This study was approved by the animal ethics committee of the governmental authorities (Regierung von Unterfranken). Approval number: AZ54-2532.1-51/12.

Statement on welfare of animals All procedures performed on animals were done in compliance with the DIRECTIVE 304 2010/63/EU of the European Parliament.

Consent to participate Not applicable.

Consent for publication Not applicable.

Conflict of interest The authors declare no competing interests.

Open Access This article is licensed under a Creative Commons Attribution 4.0 International License, which permits use, sharing, adaptation, distribution and reproduction in any medium or format, as long as you give appropriate credit to the original author(s) and the source, provide a link to the Creative Commons licence, and indicate if changes were made. The images or other third party material in this article are included in the article's Creative Commons licence, unless indicated otherwise in a credit line to the material. If material is not included in the article's Creative Commons licence and your intended use is not permitted by statutory regulation or exceeds the permitted use, you will need to obtain permission directly from the copyright holder. To view a copy of this licence, visit http://creativecommons.org/licenses/by/4.0/.

\section{References}

1. Yusuf S, Hawken S, Ounpuu S, Dans T, Avezum A, Lanas F, McQueen M, Budaj A, Pais P, Varigos J, Lisheng L (2004) Effect of potentially modifiable risk factors associated with myocardial infarction in 52 countries (the INTERHEART study): case-control study. Lancet 364:937-952. https://doi.org/10.1016/S0140-6736(04)17018-9

2. Egan BM, Li J, Hutchison FN, Ferdinand KC (2014) Hypertension in the United States, 1999 to 2012: progress toward Healthy People 2020 goals. Circulation 130:1692-1699. https://doi.org/10.1161/ CIRCULATIONAHA.114.010676

3. Muntner P, Anderson A, Charleston J, Chen Z, Ford V, Makos G, O'Connor A, Perumal K, Rahman M, Steigerwalt S, Teal V, Townsend R, Weir M, Wright JT Jr (2010) Hypertension awareness, treatment, and control in adults with CKD: results from the Chronic Renal Insufficiency Cohort (CRIC) Study. Am J Kidney Dis 55:441451. https://doi.org/10.1053/j.ajkd.2009.09.014

4. Cremer A, Amraoui F, Lip GY, Morales E, Rubin S, Segura J, Van den Born BJ, Gosse P (2016) From malignant hypertension to hypertension-MOD: a modern definition for an old but still dangerous emergency. J Hum Hypertens 30:463-466. https://doi. org/10.1038/jhh.2015.112

5. Griffin KA, Polichnowski A, Litbarg N, Picken M, Venkatachalam MA, Bidani AK (2014) Critical blood pressure threshold dependence of hypertensive injury and repair in a malignant nephrosclerosis model. Hypertension 64:801-807. https://doi.org/10.1161/ HYPERTENSIONAHA.114.03609

6. Demeulenaere M, Devreese K, Vanbelleghem H, De Zaeytijd J, Vande Walle J, Van Biesen W, Van Laecke S (2018) Thrombomodulin and endothelial dysfunction: a disease-modifier shared between malignant hypertension and atypical hemolytic uremic syndrome. Nephron 140:63-73. https://doi.org/10.1159/000490201

7. Isaacson C, Milne FJ, van Niekerk I, Kenyon MR, Mzamane DV (1991) The renal histopathology of essential malignant hypertension in black South Africans. S Afr Med J 80:173-176

8. Helmchen U, Bohle RM, Kneissler U, Groene HJ (1984) Intrarenal arteries in rats with early two-kidney, one clip hypertension. Hypertension 6:III87-92. https://doi.org/10.1161/01.hyp.6.6_ pt_2.iii87

9. Mervaala E, Muller DN, Schmidt F, Park JK, Gross V, Bader M, Breu V, Ganten D, Haller H, Luft FC (2000) Blood pressureindependent effects in rats with human renin and angiotensinogen genes. Hypertension 35:587-594. https://doi.org/10.1161/01.hyp. 35.2.587

10. Bidani AK, Griffin KA, Plott W, Schwartz MM (1994) Renal ablation acutely transforms 'benign' hypertension to 'malignant' nephrosclerosis in hypertensive rats. Hypertension 24:309-316. https://doi.org/10.1161/01.hyp.24.3.309

11. Mohring J, Petri M, Szokol M, Haack D, Mohring B (1976) Effects of saline drinking on malignant course of renal hypertension in rats. Am J Physiol 230:849-857. https://doi.org/10.1152/ ajplegacy.1976.230.3.849

12. Hartner A, Porst M, Klanke B, Cordasic N, Veelken R, Hilgers KF (2006) Angiotensin II formation in the kidney and nephrosclerosis in Ren-2 hypertensive rats. Nephrol Dial Transplant 21:1778-1785. https://doi.org/10.1093/ndt/gfl065

13. Hilgers KF, Hartner A, Porst M, Veelken R, Mann JF (2001) Angiotensin II type 1 receptor blockade prevents lethal malignant hypertension: relation to kidney inflammation. Circulation 104:1436-1440

14. Hartner A, Jagusch L, Cordasic N, Amann K, Veelken R, Jacobi J, Hilgers KF (2016) Impaired neovascularization and reduced capillary supply in the malignant vs. non-malignant course of experimental renovascular hypertension. Front Physiol 7:370. https://doi. org/10.3389/fphys.2016.00370

15. Mai M, Hilgers KF, Wagner J, Mann JF, Geiger H (1995) Expression of angiotensin-converting enzyme in renovascular hypertensive rat kidney. Hypertension 25:674-678. https://doi.org/10. 1161/01.hyp.25.4.674 
16. Schellinger IN, Cordasic N, Panesar J, Buchholz B, Jacobi J, Hartner A, Klanke B, Jakubiczka-Smorag J, Burzlaff N, Heinze E, Warnecke C, Raaz U, Willam C, Tsao PS, Eckardt KU, Amann K, Hilgers KF (2017) Hypoxia inducible factor stabilization improves defective ischemia-induced angiogenesis in a rodent model of chronic kidney disease. Kidney Int 91:616-627. https://doi.org/10.1016/j.kint.2016. 09.028

17. Mocker A, Hilgers KF, Cordasic N, Wachtveitl R, MenendezCastro C, Woelfle J, Hartner A, Fahlbusch FB (2019) Renal chemerin expression is induced in models of hypertensive nephropathy and glomerulonephritis and correlates with markers of inflammation and fibrosis. Int J Mol Sci 20. https://doi. org/10.3390/ijms20246240

18. Hrdlickova R, Toloue M, Tian B (2017) RNA-Seq methods for transcriptome analysis Wiley Interdiscip. Rev RNA 8. https:// doi.org/10.1002/wrna.1364

19. Mai M, Geiger H, Hilgers KF, Veelken R, Mann JF, Dammrich J, Luft FC (1993) Early interstitial changes in hypertensioninduced renal injury. Hypertension 22:754-765. https://doi.org/ 10.1161/01.hyp.22.5.754

20. Rodriguez-Iturbe B, Pons H, Johnson RJ (2017) Role of the immune system in hypertension. Physiol Rev 97:1127-1164. https://doi.org/10.1152/physrev.00031.2016

21. Luft FC, Dechend R, Muller DN (2012) Immune mechanisms in angiotensin II-induced target-organ damage. Ann Med 44(Suppl 1):S49-54. https://doi.org/10.3109/07853890.2011.653396

22. Cavero T, Arjona E, Soto K, Caravaca-Fontan F, Rabasco C, Bravo L, Cerda F, de la Martin N, Blasco M, Avila A, Huerta A, Cabello V, Jarque A, Alcazar C, Fulladosa X, Carbayo J, Anaya S, Cobelo C, Ramos N, Iglesias E, Baltar J, MartinezGallardo R, Perez L, Morales E, Gonzalez R, Macia M, Draibe J, Pallardo L, Quintana LF, Espinosa M, Barros X, Pereira F, Cao M, Moreno JA, Rodriguez S, Cordoba de, Praga M (2019) Severe and malignant hypertension are common in primary atypical hemolytic uremic syndrome. Kidney Int 96995 1004. https:// doi.org/10.1016/j.kint.2019.05.014

23. Timmermans S, Abdul-Hamid MA, Vanderlocht J, Damoiseaux J, Reutelingsperger CP, van Paassen P (2017) Patients with hypertension-associated thrombotic microangiopathy may present with complement abnormalities. Kidney Int 91:1420-1425. https://doi. org/10.1016/j.kint.2016.12.009

24. Larsen CP, Wilson JD, Best-Rocha A, Beggs ML, Hennigar RA (2018) Genetic testing of complement and coagulation pathways in patients with severe hypertension and renal microangiopathy. Mod Pathol 31:488-494. https://doi.org/10.1038/modpathol.2017.154

25. Coles B, Lewis R, Anning PB, Morton J, Baalasubramanian S, Morgan BP, O'Donnell VB (2007) CD59 or C3 are not requred for angiotensin II-dependent hypertension or hypertrophy in mice. Immunology 121:518-525. https://doi.org/10.1111/j.1365-2567. 2007.02598.x

26. Ruan CC, Ge Q, Li Y, Li XD, Chen DR, Ji KD, Wu YJ, Sheng LJ, Yan C, Zhu DL, Gao PJ (2015) Complement-mediated macrophage polarization in perivascular adipose tissue contributes to vascular injury in deoxycorticosterone acetate-salt mice. Arterioscler Thromb Vasc Biol 35:598-606. https://doi.org/10.1161/ ATVBAHA.114.304927

27. Negishi E, Fukuda N, Otsuki T, Katakawa M, Komatsu K, Chen L, Tanaka S, Kobayashi H, Hatanaka Y, Ueno T, Endo M, Mashimo T, Nishiyama A, Abe M (2018) Involvement of complement 3 in the salt-sensitive hypertension by activation of renal renin-angiotensin system in spontaneously hypertensive rats. Am J Physiol Renal Physiol 315:F1747-F1758. https://doi.org/10.1152/ajprenal.00370.2018

28. Wenzel UO, Bode M, Kohl J, Ehmke H (2017) A pathogenic role of complement in arterial hypertension and hypertensive end organ damage. Am J Physiol Heart Circ Physiol 312:H349-H354. https://doi.org/10.1152/ajpheart.00759.2016
29. Weiss S, Rosendahl A, Czesla D, Meyer-Schwesinger C, Stahl RA, Ehmke H, Kurts C, Zipfel PF, Kohl J, Wenzel UO (2016) The complement receptor $\mathrm{C} 5 \mathrm{aR} 1$ contributes to renal damage but protects the heart in angiotensin II-induced hypertension. Am J Physiol Renal Physiol 310:F1356-F1365. https://doi.org/10.1152/ ajprenal.00040.2016

30. Kashyap S, Osman M, Ferguson CM, Nath MC, Roy B, Lien KR, Nath KA, Garovic VD, Lerman LO, Grande JP (2018) Ccl2 deficiency protects against chronic renal injury in murine renovascular hypertension. Sci Rep 8:8598. https://doi.org/10.1038/s41598-018-26870-y

31. Alsheikh AJ, Dasinger JH, Abais-Battad JM, Fehrenbach DJ, Yang C, Cowley AW Jr, Mattson DL (2020) CCL2 mediates early renal leukocyte infiltration during salt-sensitive hypertension. Am J Physiol Renal Physiol 318:F982-F993. https://doi.org/10.1152/ ajprenal.00521.2019

32. Zimmerman KA, Bentley MR, Lever JM, Li Z, Crossman DK, Song CJ, Liu S, Crowley MR, George JF, Mrug M, Yoder BK (2019) Single-cell RNA sequencing identifies candidate renal resident macrophage gene expression signatures across species. J Am Soc Nephrol 30:767-781. https://doi.org/10.1681/ASN.2018090931

33. Norlander AE, Madhur MS, Harrison DG (2018) The immunology of hypertension. J Exp Med 215:21-33. https://doi.org/10. 1084/jem.20171773

34. Guzik TJ, Hoch NE, Brown KA, McCann LA, Rahman A, Dikalov S, Goronzy J, Weyand C, Harrison DG (2007) Role of the T cell in the genesis of angiotensin II induced hypertension and vascular dysfunction. J Exp Med 204:2449-2460. https://doi.org/10.1084/ jem.20070657

35. Seniuk A, Thiele JL, Stubbe A, Oser P, Rosendahl A, Bode M, Meyer-Schwesinger C, Wenzel UO, Ehmke H (2020) B6.Rag1 knockout mice generated at the Jackson Laboratory in 2009 show a robust wild-type hypertensive phenotype in response to Ang II (angiotensin II). Hypertension 75:1110-1116. https://doi.org/10. 1161/HYPERTENSIONAHA.119.13773

36. Vinh A, Chen W, Blinder Y, Weiss D, Taylor WR, Goronzy JJ, Weyand CM, Harrison DG, Guzik TJ (2010) Inhibition and genetic ablation of the B7/CD28 T-cell costimulation axis prevents experimental hypertension. Circulation 122:2529-2537. https://doi.org/10.1161/CIRCULATIONAHA.109.930446

37. Wuyts A, Van Osselaer N, Haelens A, Samson I, Herdewijn P, Ben-Baruch A, Oppenheim JJ, Proost P, Van Damme J (1997) Characterization of synthetic human granulocyte chemotactic protein 2: usage of chemokine receptors CXCR1 and CXCR2 and in vivo inflammatory properties. Biochemistry 36:2716-2723. https://doi.org/10.1021/bi961999z

38. Liu X, Zhang Q, Wu H, Du H, Liu L, Shi H, Wang C, Xia Y, Guo X, Li C, Bao X, Su Q, Sun S, Wang X, Zhou M, Jia Q, Zhao H, Song K, Niu K (2015) Blood neutrophil to lymphocyte ratio as a predictor of hypertension. Am J Hypertens 28:1339-1346. https:// doi.org/10.1093/ajh/hpv034

39. Wu Y, Li Y, Zhang C, A X, Wang Y, Cui W, Li H, Du J (2014) $\mathrm{S} 100 \mathrm{a} 8 / \mathrm{a} 9$ released by $\mathrm{CD} 11 \mathrm{~b}+\mathrm{Gr} 1+$ neutrophils activates cardiac fibroblasts to initiate angiotensin II-Induced cardiac inflammation and injury. Hypertension 63:1241-1250. https://doi.org/10.1161/ HYPERTENSIONAHA.113.02843

40. Ofosu-Appiah W, Sfeir G, Smith D, Richard T (1997) Neutrophilmediated damage to vascular endothelium in the spontaneously hypertensive rat. Clin Immunol Immunopathol 83:293-301. https://doi.org/10.1006/clin.1997.4361

41. Percie du Sert N, Hurst V, Ahluwalia A, Alam S, Avey MT, Baker M, Browne WJ, Clark A, Cuthill IC, Dirnagl U, Emerson M, Garner P, Holgate ST, Howells DW, Karp NA, Lazic SE, Lidster K, MacCallum CJ, Macleod M, Pearl EJ, Petersen OH, Rawle F, Reynolds P, Rooney K, Sena ES, Silberberg SD, Steckler T, Wurbel H (2020) The ARRIVE guidelines 2.0: Updated guidelines for reporting animal research. PLoS Biol 18:e3000410. https://doi.org/10.1371/journal.pbio.3000410 
42. Menendez-Castro C, Toka O, Fahlbusch F, Cordasic N, Wachtveitl R, Hilgers KF, Rascher W, Hartner A (2014) Impaired myocardial performance in a normotensive rat model of intrauterine growth restriction. Pediatr Res 75:697-706. https://doi.org/10.1038/pr. 2014.27

43. Heiss RU, Fahlbusch FB, Jacobi J, Daniel C, Ekici AB, Cordasic N, Amann K, Hartner A, Hilgers KF (2017) Blunted transcriptional response to skeletal muscle ischemia in rats with chronic kidney disease: potential role for impaired ischemia-induced angiogenesis. Physiol Genomics 49:230-237. https://doi.org/10. 1152/physiolgenomics.00124.2016

44. Fleige S, Pfaffl MW (2006) RNA integrity and the effect on the real-time qRT-PCR performance. Mol Aspects Med 27:126-139. https://doi.org/10.1016/j.mam.2005.12.003
45. Matsui K, Nagy-Bojarsky K, Laakkonen P, Krieger S, Mechtler K, Uchida S, Geleff S, Kang DH, Johnson RJ, Kerjaschki D (2003) Lymphatic microvessels in the rat remnant kidney model of renal fibrosis: aminopeptidase $\mathrm{p}$ and podoplanin are discriminatory markers for endothelial cells of blood and lymphatic vessels. J Am Soc Nephrol 14:1981-1989. https://doi.org/10.1097/01.asn. 0000076078.50889 .43

46. Evans JD (1996) Straightforward statistics for the behavioral sciences. Brooks/Cole Pub. Co., Pacific Grove

Publisher's Note Springer Nature remains neutral with regard to jurisdictional claims in published maps and institutional affiliations.

\section{Authors and Affiliations}

\section{Carlos Menendez-Castro ${ }^{1}$ - Nada Cordasic ${ }^{2}$ - Fabian B. Fahlbusch ${ }^{1}$ - Arif B. Ekici ${ }^{3}$ - Philipp Kirchner ${ }^{3}$. Christoph Daniel $^{4} \cdot$ Kerstin Amann $^{4} \cdot$ Roland Velkeen $^{2} \cdot$ Joachim Wölfle $^{1} \cdot$ Mario Schiffer $^{2} \cdot$ Andrea Hartner $^{1}(1)$. Karl F. Hilgers ${ }^{2}$}

1 Department of Pediatrics and Adolescent Medicine, University Hospital Erlangen, Friedrich-Alexander University of Erlangen-Nürnberg, Erlangen, Germany

2 Department of Nephrology and Hypertension, University Hospital Erlangen, Friedrich-Alexander University of Erlangen-Nürnberg, Ulmenweg 18, 91054 Erlangen, Germany
3 Institute of Human Genetics, University Hospital Erlangen, Friedrich-Alexander University of Erlangen-Nürnberg, Erlangen, Germany

4 Institute of Nephropathology, University Hospital Erlangen, Friedrich-Alexander University of Erlangen-Nürnberg, Erlangen, Germany 